\title{
İnşaat Projelerinde Zaman Maliyet Ödünleşim Problemi: Örnek Olay Analizi
}

\author{
Mehmet Nurettin Uğural ${ }^{1 *}$ \\ 1 İstanbul Kültür Üniversitesi, Mühendislik Fakültesi, İnşaat Mühendisliği Bölümü, İstanbul, Türkiye (ORCID: 0000-0002-8037-7603)
}

(İlk Geliş Tarihi 25 Nisan 2020 ve Kabul Tarihi 16 Haziran 2020)

(DOI: 10.31590/ejosat.726891)

ATIF/REFERENCE: Uğural, M. N. (2020). İnşaat Projelerinde Zaman Maliyet Ödünleşim Problemi: Örnek Olay Analizi. Avrupa Bilim ve Teknoloji Dergisi, (19), 460-465.

\section{$\ddot{O} \mathbf{z}$}

Globalleşen dünyada artan rekabet koşullarıla birlikte inşaat projelerinin gerek zaman gerekse maliyet olarak optimize edilmesi kaçınılmaz bir hal almıştır. Bu ortamda proje yöneticisinin karşı karşıya olduğu en önemli zorluklardan biri, projeye ayrılan zaman ve finansal kaynak kısıtları içerisinde istenilen kalite standartlarına göre projenin yapılabilirliğine karar vermek ve sonrasında tamamlanmasını sağlamaktır. Günümüzde proje yöneticileri sürekli bir zaman ve maliyet indirgenmesi baskısıyla karşı karşıyadır. Bu noktada her bir proje için zaman ve maliyet ödünleşiminin nasıl yapılacağı ve hangi türden bir model geliştirileceği proje yöneticilerinin üzerinde çalıştı̆̆ı en ciddi problemlerden birisi olarak karşımıza çıkar. Bu çalışmada, proje kısıtlamaları altında zaman ve maliyeti en aza indirmeyi amaçlayan CPM tabanlı bir proje hızlandırma modeli sunulmaktadır. Geliştirilen model örnek bir inşaat projesine ait derlenmiş verilerle uygulanmıştır. Araştırmada ilk olarak hızlandırma sürelerini ve maliyetlerini bulmak için kritik yol yöntemi (CPM) kullanılarak kritik yol ve bu yol üzerindeki kritik aktiviteler belirlenmiştir. Projede yer alan faaliyetlerin sürelerinin deterministik olduğu öngörülmüştür. Probleme ilişkin amaç fonksiyonunun belirlenmesi için kritik yol üzerindeki her bir faaliyetin hızlandırma maliyetleri ve maliyet eğimleri hesaplanmıştır. Oluşturulan modeldeki zaman ve maliyet parametreleri arasındaki ilişkiyi tanımlayabilmek için problem MATLAB programı ile çözülmüştür. Analiz sonucunda projenin 19 haftadan 13 haftaya kadar kısaltılabileceği hesaplanırken, en uygun 741 bin TL. bütçe ve 2 hafta hızlandırmayla toplam 17 haftada tamamlanabileceği görülmüştür.

Anahtar Kelimeler: İnşaat proje yönetimi, hızlandırma, kritik yol metodu, (CPM), zaman maliyet ödünleşimi,

\section{Time-Cost Trade-Off Analysis in a Construction Projects: Case Study}

\begin{abstract}
This is a very difficult challenge for project managers in today's competitive world to complete a project within time and budget. In this environment, one of the most important challenges faced by the project manager is to decide on the feasibility of the project by the desired quality standards within the time frame and the financial resources allocated to the project. The cost and time of the project always play a vital role in the decision of the construction projects. Project managers today are faced with constant pressures in terms of time and cost management. At this point, it is one of the most serious problems for project managers to work on how to make time and cost trade-offs and what kind of models to develop. The objective of the time-cost trade-off analysis is to reduce the duration of the original project at the lowest possible total cost. The main purpose of this study is to demonstrate, in a simply and understandable way, how the time of the project is reduced by the time-cost trade-off analysis of the project. Secondly, to determine the optimum point between time and cost. In this paper, critical path method is used to find out the duration and the cost of the crashing with heuristic method. The duration of the project activities is predicted to be deterministic. Regression analysis is carried out to identify the relationship between time and cost in order to formulate a quadratic model. The analysis reveals that through proper scheduling of all activities, the project can be completed within 13 weeks from estimated 19 weeks. The problem is then solved by the MATLAB program, which has an optimum cost of at least 741.000 TL. with a duration of 17 to weeks.
\end{abstract}

Keywords: Construction Project Management, Critical Path, Time-Cost Trade-Off Analysis, Crashing.

\footnotetext{
* Sorumlu Yazar: İstanbul Kültür Üniversitesi, Mühendislik Fakültesi, İnşaat Mühendisliği Bölümü, İstanbul, Türkiye (ORCID: 0000-0002-80377603), m.ugural@iku.edu.tr
} 
European Journal of Science and Technology

\section{Giriş}

İnşaat projelerinin planlanması ve kontrolünde zaman-maliyet ödünleşimi sıklıkla gündeme gelen önemli sorunlardan biridir. Maliyet ile süre arasında ters yönlü bir ilişkinin olması, yani proje zamanı kısaltıldığında maliyetinin artması, proje yöneticilerini zaman-maliyet ödünleşimi konusunda optimum denge noktasını bulma arayışına sokmuştur (Karaman ve Kale,2007). Ne kadar mükemmel planlama yapılırsa yapılsın yerel ve uluslararası ekonomik dalgalanmalar projelerin başlangıçta tespit edilen zaman ve maliyet parametreli sınırlarında tamamlanmasını çok büyük oranda imkânsızlaştırmaktadır (Geem, 2010; Sorrentino, 2013; Haque ve Hasin,2012;). İnşaat projelerinde doğru bir iş programı, verimli makine ve iş gücü kullanımı projenin öngörülen zamanda tamamlanmasına olanak sağlamaktadır. Ancak işgücü, yüklenici, lojistik, hava ve mevsim şartları gibi kısmen öngörülebilen faktörlerle, salgın hastalık beklenmeyen olaylar, doğal afetler gibi öngörülemeyen olaylar iş programında gecikmeye neden olabilmektedir. Bu gecikmelerin dışında; değişen ekonomik koşullar ve artan risk olgusuyla projenin erken tamamlanması maliyete bakılmaksızın zorunlu hale gelebilir. Bu durumda proje yöneticileri normal zamandan daha kısıtlı bir zaman diliminde projeyi tamamlamak zorunda kalabilmektedir. Zaman ve maliyet ödünleşimi projenin optimum şekilde tamamlanması için zaman ve maliyet arasındaki geçişlerin dengelenmesi anlamına gelmektedir (Martin vd., 2006; Eshtehardian vd., 2008;). Projenin tamamlanmasını hızlandırmak için, proje yöneticilerinin daha fazla veya daha üretken işgücü ve ekipman kullanarak planlanan yürütme zamanını kısaltması gerekir. Bu hedef zaman, proje faaliyetlerine fazladan işgücü atanarak, fazla mesai veya işe alma şeklinde faaliyet zamanlarını azaltarak veya malzeme ve ekipman gibi diğer ek kaynak türlerini projeye ilave ederek karşılanabilir. Proje zamanı sıkıştırıldığında, proje yöneticilerinin artan talebi karşılamak için daha fazla maddi kaynağa ihtiyaç duydukları ve bu durumun proje maliyetini normalin daha üstünde artırdığı açıktır. Hızlandırmada zaman azaldıkça maliyet artacaktır. Bu şekilde zaman ile maliyet arasına ters yönlü bir ilişki mevcuttur (Aziz, 2013; Parveen ve Saha, 2012). Proje içerisinde aktivite zamanının kısaltılması, hızlandırma (crashing) veya çökme olarak adlandırılır (Lui vd. 1995; Pour vd.,2012). Bu durum proje maliyetini arttıracağı için proje zamanını kısaltma kararı, zaman ve maliyet arasındaki optimum dengenin belirlenmesini gerektirir. Ancak ilave yapılan bu harcamanın verimli olabilmesi için ek maliyetin projenin tüm faaliyetleri yerine kritik yol üzerindeki faaliyetlerin tamamlanma zamanını kısaltmakta kullanılması gerekmektedir. Zaman ve maliyet arasındaki ödünleşim süreci, kritik yol üzerindeki faaliyetlerin hızlandırılması temelinde gerçekleşir. İnşaat maliyeti doğrudan ve sabit giderlerin toplamı olarak hesaplandığından dolayı projenin kritik yolunda oluşacak hızlanma sonucunda proje (doğrudan) maliyetinin artmasına karşın sabit maliyetlerdeki azalma, toplam maliyeti düşürecektir. Amaç projenin tamamlanma süresini belirli aktivitelerde kısıtlı maliyet artışı yaparak bir anlamda asgari kaynak harcamasıyla en aza indirmektir (Shahsavari vd.,2010).

Proje yönetimi, en genel tanımıyla projelerin amaçlarına ulaşması için faaliyetlerinin planlanması, programlanması ve kontrol edilmesi olarak adlandırabilir. Akademik anlamda proje yönetimi "tekrarı olmayan; zaman, kapsam, bütçe ve kalite kısıtlarını barındıran faaliyetlerin yönetilmesi süreci” olarak tanımlanmaktadır (PMI, 2008; Gido ve Clements 2006, 18). Kritik yol metodu (CPM) ve proje değerlendirme ve gözden geçirme tekniği (PERT) proje yönetiminde proje zaman planlamasında sıklıkla kullanılan iki önemli tekniktir. $\mathrm{Bu}$ teknikler proje yöneticilerine projenin süreçlerinin izlenmesinde yardımcı olurlar. İki teknik arasındaki temel fark kritik yol metodunun (CPM) deterministik sürelere, proje değerlendirme ve gözden geçirme metodunun (PERT) ise olasılıksal sürelere dayanmasıdır. Proje yönetiminde zaman maliyet ödünleşim problemleri, genel anlamıyla faaliyetlerin normal zamanlarını mümkün olan en düşük maliyetle hızlandırarak proje tamamlanma süresi için belirli bir son tarih elde etme amacı taşımaktadır. Zaman-maliyet ödünleşim problemi TCTP (time cost trade-off problem), öncelik kısıtlamaları ile proje yönetiminde yaygın olarak ele alınan konulardan birisidir. Bir proje, öncelik kısıtlamalarına tabi olarak programlanması gereken normal süresi belirlenmiş faaliyetlerden oluşur (Hegazy,1999). Projenin en erken bitiş zamanı, tüm faaliyetlerin öncelik kısıtlamalarına tabi olarak gerçekleştirileceği projenin en uzun yolu olarak tanımlanmaktadır. Temelde zaman maliyet ödünleşim problemleri, azaltılmış zaman periyotlarının bir fonksiyonu olarak lineer veya kuadratik programlama teknikleri kullanılarak çözülebilir. Günümüzde bu amaçla çeşitli paket programlar (Lindo, Lingo Matlab, QM for Windows vb.) yaygın olarak kullanılsa da zaman maliyet ödünleşiminin veya proje hızlandırmanın temel mantığının klasik basit matematiksel yöntemlerle açıklanmasının gerekli olduğu düşünülmektedir. Zaman maliyet ödünleşimi, proje çizelgeleme, öncelik kısıtlamaları ile çizelgeleme veya belirli faaliyetlere ek kaynaklar tahsis etme yöntemiyle hızlandırma problemleri üzerinde sıklıkla çalışılan ve geniş bir literatüre sahip konulardır (Arditi ve Tokdemir, 2001; Ballesteros, 2018; Creemers, 2019; Gürbüz vd., 2020). Zaman maliyet ödünlemişine ilişkin Kelly (1961)'den başlamak üzere günümüze kadar çok sayıda çalışma yapılmıştır (Rayes ve Kandil, 2005; Bettemir ve Birgönül, 2012; Haghighi vd., 2019). Bu problemleri çözmek için kullanılan teknikler temel olarak deterministik ve sezgisel olmak üzere iki ana gruba ayrılmıştır (Suhail ve Neale 1994; Azaron vd., 2005; Elazouni vd., 2007; Razek vd., 2010, Burgan 2020). Matematiksel programlama yöntemleri olarak lineer, kuadratik, dinamik ve tam sayılı programlama, dal ve sinır yöntemleri ile benzetim tabanlı yöntemler gösterilebilirken sezgisel programlama yöntemleri olarak genetik algoritma tabanlı karınca kolonisi, bulanık çok amaçlı genetik algoritma ve minimum maliyet algoritması örnek olarak verilebilir.

$\mathrm{Bu}$ araştırmada kritik faaliyetleri, bollukları ve proje süresini belirlemek için deterministik programlama tekniklerinden biri olan kritik yol metodu (CPM) kullanılmıştır. Kritik yol metodunda bir proje ağı tanımlanıp faaliyetlerin gösterilmesi sürecinde iki ana çizim yaklaşımı vardır: Birincisi AOA kısaltmasıyla faaliyetleri ok üzerinde gösterimi, ikincisi AON kısaltmasıyla faaliyetlerin dügüum noktaları üzerinde gösterimidir. Faaliyetlerin düğüm noktaları üzerinde gösterilmesi şeklinde formüle edilen AON diyagramında her bir aktivite için bir düğüm noktası, her bir öncelik ilişkisini göstermek için de oklardan istifade edilir. Faaliyetlerin oklar üzerinde gösterilmesi şeklinde ifade edilen AOA diyagramında ise her bir faaliyet oklar üzerinde gösterilir. Çalışmanın amacı örnek olarak ele alınan proje üzerinde sade ve anlaşılabilir bir şekilde zaman-maliyet ödünleşim analizi ile proje süresinin nasıl indirgendiğini göstermektir. Çalışmada ilk olarak hızlandırma sürelerini ve maliyetlerini bulmak için kritik yol yöntemi (CPM) kullanılarak kritik yol ve bu yol üzerindeki kritik aktiviteler belirlenmiştir. Projede yer alan faaliyetlerin sürelerinin deterministik olduğu öngörülmüştür. Probleme ilişkin amaç fonksiyonunun belirlenmesi için kritik yol üzerindeki her bir faaliyetin hızlandırma maliyetleri ve maliyet eğimleri hesaplanmıştır. Optimizasyon modeli oluşturarak zaman ve maliyet parametreleri arasındaki ilişkiyi tanımlayabilmek için oluşturulan problem MATLAB programı yardımıyla çözülmüştür. 


\section{Materyal ve Metot}

Çalışmada kullanılacak olan inşaat problemi için gerekli olan veriler daha önce eğitim amaçlı olarak kullanılan ikincil bir kaynaktan alınmış olup projenin kritik faaliyetleri ve kritik yolunu hesaplamak için kritik yol metodu (CPM) uygulanmıştır. Kritik yol üzerinde yer alan faaliyetlerin en düşük maliyet eğimlerini elde etmek için faaliyetler belli sürelerde kısaltılmıştır. Bilindiği üzere 'maliyet eğimi' terimi, projede "her bir birim zaman azalmasına karşılık maliyette meydana gelen artışı" olarak tanımlanır. Matematiksel olarak maliyet eğimi $=$ (hızlandırma maliyeti- normal maliyet) / (normal süre- hızlandırma süresi) şeklinde hesaplanır. Kritik yol üzerindeki faaliyetlerin süreleri kısaldıkça projenin süresi de kısalacak ve başka bir yol, kritik yol haline gelebilecektir. Bu şekilde oluşturulacak zaman çizelgesi her bir yeni hesaplamanın sonucunda tekrar belirlenmiş, zaman-maliyet ödünleşim (TCTP) problemi Matlab yazılımını kullanarak toplam maliyeti en aza indirmek ve projenin hızlandırma (crashing) süresini planlamak için analiz edilmiştir. Bu noktaya kadar anlatılan proje süresinin hızlandırılması problemi aşağıdaki adımlarda özetlenebilir:

Adım 1: Proje ağının çizilmesi

Adım 2: Kritik yol metodu (CPM) ile belirtilen tüm aktiviteler için normal süreleri kullanarak kritik aktivitelerin ve projenin kritik yolunun belirlenmesi.

Adım 3: Her aktivite için süre maliyet eğiminin hesaplanması.

Adım 4: Kritik yol üzerindeki en düşük maliyet eğimindeki aktiviteden başlayarak faaliyetlerin hızlandırılması. Bu işlem kritik yol üzerindeki faaliyetlerde yapılabilecek olan tüm hızlandırmalar sona erinceye kadar devam edecektir. Projede aynı anda iki farklı yol olması durumunda her ikisinin de olası hızlandırma maliyetleri hesaplanarak hızlandırma maliyet eğimi en düşük olan yoldan devam edilecektir.

Adım 5: Projenin tamamlanma süresi-yığışımlı maliyet artışı arasındaki ilişkinin Matlab ile grafiksel gösterimi. Bu eğri optimum süreyi ve karşılık gelen minimum maliyet değerini verir.

\section{Araştırma Sonuçları ve Tartışma}

Çalışmanın matematiksel analizinde ara işlemlerin kolaylıkla görülebilmesi açısından karmaşık olmayan 7 aktiviteden oluşan bir inşaat projesi örnek olarak seçilmiştir. Tablo 1'de projeye ilişkin bilgiler verilmiştir.

\begin{tabular}{l|l|l|l}
\multicolumn{2}{|c}{ Tablo 1: Örnek projeye ilişkin veriler. } & Märe (hafta) & Maliyet (Bin TL) \\
\hline A & Öncülü & 5 & 50 \\
\hline B & - & 4 & 35 \\
\hline C & A & 5 & 60 \\
\hline D & A & 3 & 40 \\
\hline E & A & 8 & 100 \\
\hline F & B, C & 6 & 75 \\
\hline G & C, D & 1 & 20 \\
\hline
\end{tabular}

Tablo 1'de öngörülen verilere dayalı olarak aşağıda Şekil 1'de AON yöntemi kullanılarak proje de yer alan her bir faaliyetin en erken ve en geç başlangıç ve bitiş süreleri ile serbest ve toplam bollukları hesaplanmıştır. Bu işlemlerin sonucunda projenin kritik yolu A-C-E-G olarak belirlenmiş, proje süresi 19 hafta doğrudan proje maliyeti 380 bin TL olarak hesaplanmıştır.

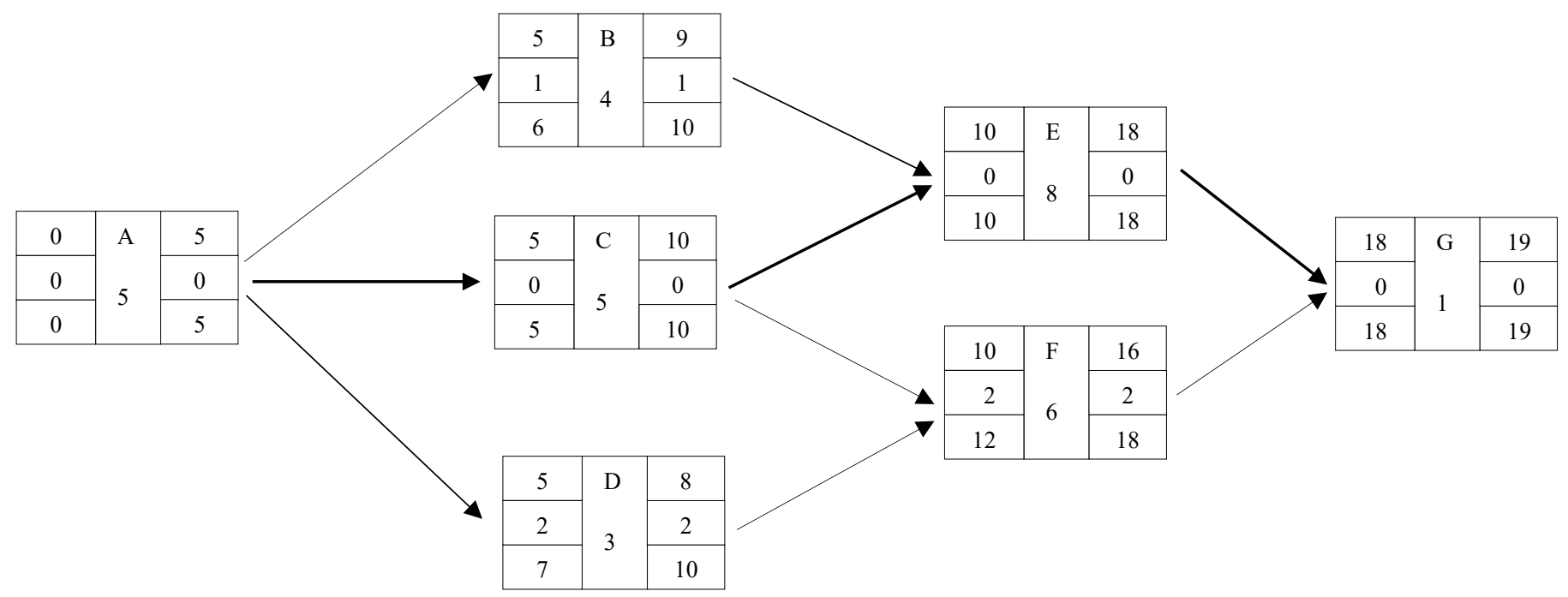

Şekil 1: Örnek projeye ilişkin şebeke diyagramı.

Beklenen proje süresini hızlandırarak 19 haftadan daha bir kısa sürede tamamlamak için, zaman maliyet ödünleşimi öngörülmüştür. Yukarıda da açıklandığı üzere proje süresinin kısaltılması ekstra fazla mesai, ek işçi alımı, özel makine ve ekipman kullanımı gibi çeşitli ilave maliyet getiren önlemlerle gerçekleştirilebilir. Bu durumda proje süresi kısaldıkça projenin sabit giderlerinde bir azalma olacak ve 
projenin toplam maliyeti düşecektir. Bu çalışmada proje sabit gideri haftalık 20 bin TL olarak öngörülmüştür. Tablo 2'de sabit giderler olmaksızın doğrudan proje maliyetleri üzerinden projenin hızlandırılmış süre ve maliyetleri ile maliyet-zaman eğimleri görülmektedir.

Tablo 2: Hızlandırma Süre ve Maliyetleri ile Maliyet-Zaman Eğimi Tablosu

\begin{tabular}{l|l|l|l|l|l|l|l} 
& \multicolumn{2}{|c|}{ Normal } & \multicolumn{2}{c|}{ Hızlandırılmış } & \multicolumn{3}{c}{ Süre-Maliyet Ĕ̈imleri } \\
\hline Faaliyet kodu & $\begin{array}{l}\text { Süre } \\
(\text { Hafta) }\end{array}$ & $\begin{array}{l}\text { Maliyet } \\
(\text { Bin TL) }\end{array}$ & $\begin{array}{l}\text { Süre } \\
(\text { Hafta) }\end{array}$ & $\begin{array}{l}\text { Maliyet } \\
(\text { Bin TL) }\end{array}$ & $\begin{array}{l}\text { HM-NM } \\
(\Delta \mathbf{C})\end{array}$ & $\begin{array}{l}\text { HS-NS } \\
(\Delta \mathbf{t})\end{array}$ & $\begin{array}{l}\text { Eğim } \\
(\Delta \mathbf{C}) /(\Delta \mathbf{t})\end{array}$ \\
\hline A & 5 & 50 & 4 & 100 & 50 & 1 & 50 \\
\hline B & 4 & 35 & 3 & 40 & 5 & 1 & 5 \\
\hline C & 5 & 60 & 3 & 150 & 90 & 2 & 45 \\
\hline D & 3 & 40 & 2 & 45 & 5 & 1 & 5 \\
\hline E & 8 & 100 & 5 & 130 & 30 & 3 & 10 \\
\hline F & 6 & 75 & 5 & 90 & 15 & 1 & 15 \\
\hline G & 1 & 20 & 1 & 20 & 0 & 0 & 0 \\
\hline
\end{tabular}

HM: Hızlandırılmış Maliyet NM: Normal Maliyet NS: Normal Süre HS: Hızlandırma Süresi

Birinci hızlandırmada projenin kritik yolu olan A-C-E-G yolunda en düşük eğime (birim maliyete) sahip olan faaliyet, G faaliyetidir. G faaliyetinin eğimi sıfır olduğu için bu faaliyette hızlandırma yapılamaz. Sonraki hızlandırma kritik yol üzerindeki en düşük eğime sahip ikinci faaliyet olan E faaliyeti üzerinde yapılmalıdır. E faaliyeti normal şartlarda üç hafta hızlandırılabilmesine rağmen üç hafta hızlandırıldığı takdirde projenin kritik yolu değişeceği (ACFG bakınız Şekil 1) için proje ilk etapta projenin kritik yolunu değiştirmeyecek limitte iki hafta hızlandırılmış ve toplam proje süresi 17 haftaya, proje maliyet ise $10 * 2=20$ bin TL artarak 400 bin TL'ye çıkmıştır. Bu durumda projede 2 farklı kritik yol (ACEG 17 hafta ve ACFG 17 hafta) oluşmuştur. Yapılan bu hızlandırmadan sonra $\mathrm{A}$ ve $\mathrm{C}$ faaliyetlerinin yanında, $\mathrm{E}$ faaliyetinden sonra $\mathrm{F}$ faaliyeti de kritik faaliyet durumuna gelmiştir. Bu nedenle tek başına $\mathrm{E}$ faaliyetinde yapılacak olan bir hızlandırma proje süresini kısaltmayacaktır. İkinci hızlandırmada projenin kısaltılabilmesi için E faaliyeti (birinci hızlandırmada bir haftalık hızlandırma süresi kalmışıı) ile aynı anda $\mathrm{F}$ faaliyeti de hızlandırılmalıdır. $\mathrm{E}$ ve $\mathrm{F}$ faaliyetlerinin birim maliyetleri (eğimleri) toplandığında $(10+15=25$ bin $\mathrm{TL})$, $\mathrm{E}$ ve $\mathrm{F}$ faaliyetleri $\mathrm{A}$ ve $\mathrm{C}$ faaliyetlerinin eğimlerine göre daha düşük olduğu için aynı anda birer hafta hızlandırılmıştır. Bu durumda projenin mevcut kritik yolu (ACEG ve ACFG) değişmezken maliyet 25 bin TL artarak 425 bin TL'ye yükselmiş, proje süresi ise 1 hafta kısalarak 16 haftaya düşmüştür. Üçüncü hızlandırmada projede artık E, F ve $\mathrm{G}$ faaliyetleri hızlandırılamayacağına göre sadece kritik yol üzerinde bulunan A veya $\mathrm{C}$ faaliyetleri hızlandırılabilir. A ve $\mathrm{C}$ faaliyetlerinden en düşük eğime sahip olan $\mathrm{C}$ faaliyeti olduğu için $\mathrm{C}$ faaliyeti 1 hafta hızlandırılmıştır. Yukarıda birinci hızlandırmada yaşanan benzer durum burada tekrar oluşmuştur. C faaliyeti normal şartlarda iki hafta hızlandırılabilmesine rağmen iki hafta hızlandırıldığı takdirde projenin kritik yolu değişeceği (ADFG bkz. Şekil 1) ve D faaliyeti de kritik faaliyet durumuna geçeceği için proje ilk etapta kritik yolu değiştirmeyecek limitte bir hafta hızlandııılmıştır. Bu işlem sonunda proje maliyeti 45 bin TL artarak 470 bin TL'ye yükselmiş, proje süresi ise 15 haftaya düşmüştür. Yeni durumda projede üç farklı kritik yol (ACEG, ACFG ve ABEG) oluşmuş ve B faaliyeti de oluşan yeni durumda kritik faaliyet durumuna gelmiştir. Dördüncü hızlandırma için kritik yol üzerindeki faaliyetlerin eğimlerini incelediğimizde A faaliyetinin 50 bin TL'ye bir hafta hızlandırılabileceği veya A faaliyeti yerine $\mathrm{B}$ ve $\mathrm{C}$ faaliyetlerinin eğimleri toplamının A faaliyetinin eğimine eşit olduğun $(45+5=50$ bin $\mathrm{TL})$ görüldüğünden, rastgele $\mathrm{A}$ faaliyetinin hızlandırılmasına karar verilmiştir. Bu işlem sonunda projenin maliyeti 50 bin TL artarak 520 bin TL'ye yükselmiş proje süresi ise 14 haftaya düşmüştür. Beşinci ve son hızlandırmada, dördüncü hızlandırmada rastgele $\mathrm{A}$ faaliyetinin tercih edilmesi sonucu tercih edilmeyen $\mathrm{B}$ ve $\mathrm{C}$ faaliyetleri aynı anda bir hafta hızlandırılmıştır. Bu durumda projedeki bütün faaliyetler kritik faaliyet durumuna gelmiş projenin süresi 13 haftaya düşmüş, proje maliyet ise 570 bin TL'ye yükselmiştir. Bu durumda proje süresi toplamda 6 gün kısalmış ve proje maliyeti ise190 bin $\mathrm{TL}$ artmıştır. Yapılan tüm bu hesaplamalara sabit maliyetlerde dahil edildikten sonra inşaat projesinin tamamlanması için öngörülen zamanın toplam maliyete göre değişimi Tablo 3’te, maliyet ve zaman arasındaki regresyon analizi grafiği ise Şekil 2'de gösterilmiştir.

Tablo 3: Hızlandirma Sonuçlarına Göre Süre-Maliyet ve Kritik Yol Değişim Tablosu

\begin{tabular}{l|l|l|l|l|l} 
Hızlandırma No & Süre (Hafta) & $\begin{array}{l}\text { Sabit Maliyet } \\
\text { (Bin Tl) }\end{array}$ & $\begin{array}{l}\text { Proje Maliyeti } \\
(\text { Bin Tl) }\end{array}$ & $\begin{array}{l}\text { Toplam Maliyet } \\
(\text { Bin Tl) }\end{array}$ & Kritik Yol \\
\hline 0 & 19 & 380 & 380 & 760 & ACEG \\
\hline 1 & 17 & 340 & 400 & 740 & ACEG/ACFG \\
\hline 2 & 16 & 320 & 425 & 745 & ACEG/ACFG \\
\hline 3 & 15 & 300 & 470 & 770 & ACEG/ACFG/ABEG \\
\hline 4 & 14 & 280 & 520 & 800 & ACEG/ACFG/ABEG \\
\hline 5 & 13 & 260 & 570 & 830 & ACEG/ACFG/ABEG \\
\hline
\end{tabular}


Figure 1

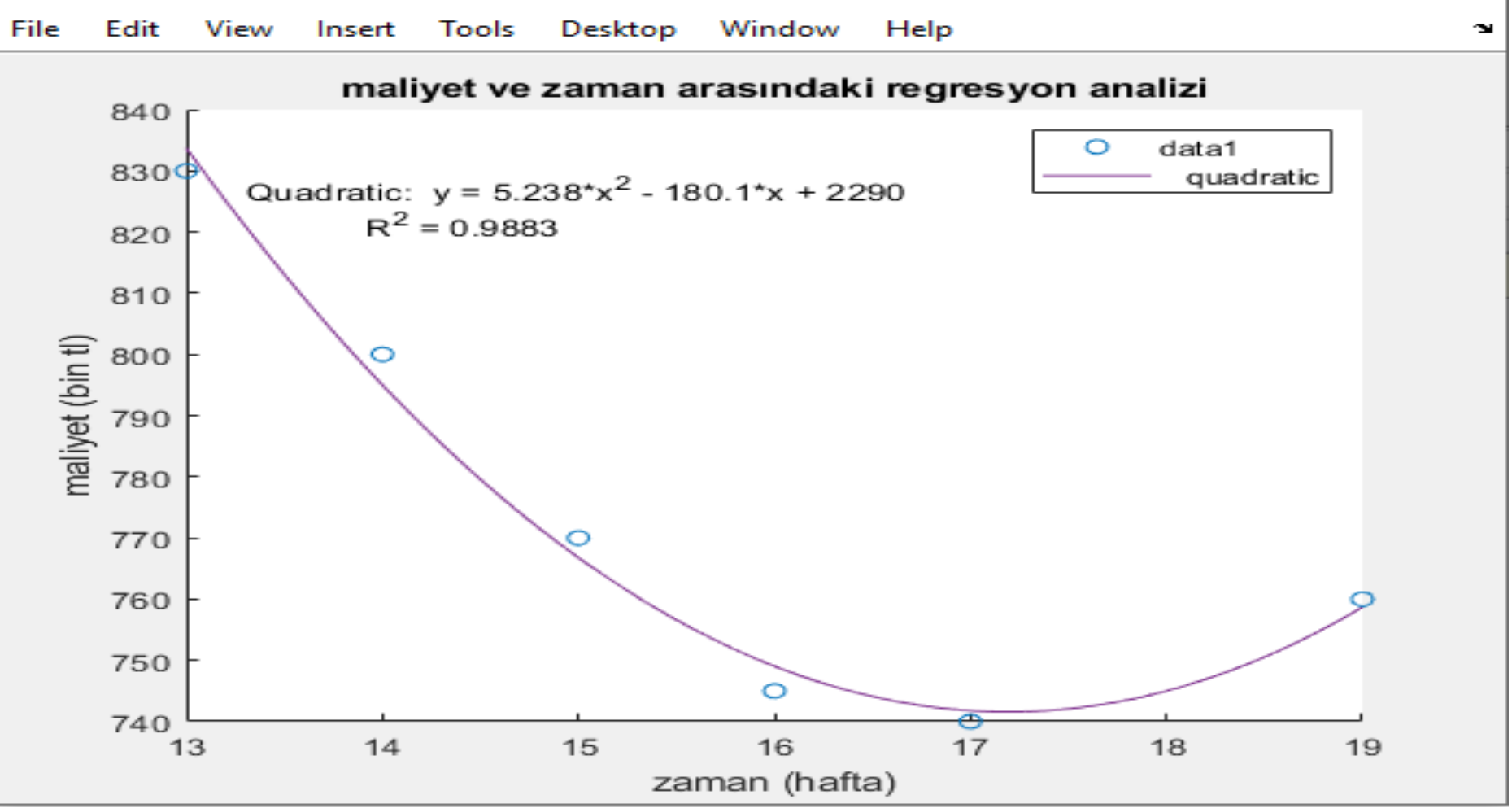

Şekil 2: Maliyet ve zaman arasındaki regresyon analizi

Şekil 2'deki grafikte Matlab programı yardımıyla oluşturulan maliyet ve zaman arasındaki değişim eğrisi ve problemin minimize edilmesi için gerekli olan kuadratik programlama denklemi görülmektedir. Bu modelin amacı, inşaat projesinin toplam süresi olan 19 hafta ile en fazla süre kısaltmasının (hızlandırmanın) yapılabileceği 13 hafta arasında toplam maliyetin (Min Z) en az olduğu noktayı hesaplayabilmektir. Probleme ilişkin Matlab programı tarafından oluşturulan denklem aşağıda verilmiştir.

Min $Z=5.238 \mathrm{x}^{2}-180,1 \mathrm{x}+2290$ (denklemde $\mathrm{x}$ : projenin tamamlanma süresini ifade etmektedir)

Probleme ilişkin alınan zaman kısıtı ise; $13 \leq \mathrm{x} \leq 19$ olarak tanımlanmıştır.

Program tarafından oluşturulan bu denklem çözüldüğünde projenin en optimal tamamlanma süresi 17 gün ve toplam en düşük maliyet ise 741 bin TL olarak bulunmuştur.

\section{Sonuç}

İşsaat projelerinde zaman ve toplam maliyet birbirleriyle ters orantılı faktörlerdir. Proje zamanının kısaltılması için projenin hızlandırılması ilave maliyet artışı gerektirir. Şekil 2'de görüleceği üzere proje süresi kısaldıkça projenin maliyeti artmaktadır. Hızlandırma işleminde bir süre sonra, toplam maliyet minimum değerine ulaşır ve bundan sonraki hızlandırmalarda maliyet artışı efektif olmaktan çıkar. Bu durum, inşaat projelerinin gerçek davranışını ortaya koyarak inşaat projelerinin farklı ve genellikle birbiriyle çelişen yönleri arasında uzlaşma sağlamak için optimum kaynak kullanımının zorluğunu göstermektedir. Regresyon analizi, hızlandırma süreleri ile hızlandırma maliyetleri arasındaki ilişkiyi göstermektedir. Bu araştırmada bir inşaat projesinin faaliyetlerinin, projenin yürütülmesini hızlandıracak şekilde zaman-maliyet ödünleşim analizi yardımıyla programlanması açıklanmıştır. Kritik yol metodu ile projenin kritik faaliyetleri ve toplam süresi belirlenmiş, Matlab programı yardımıyla optimal hızlandırma süresi ve proje maliyeti hesaplanmıştır. Araştırmada ele alınan projenin, zaman-maliyet denge analizi, 17 gün ve 741 bin TL olarak bulunmuştur. Bu araştırmada projenin zaman ve maliyet verileri belirlenirken deterministik yöntemler kullanılmış, proje genelinde oluşabilecek ve projeyi etkileyecek belirsizlikler göz ardı edilmiştir. Araştırmada ele alınan basit örnek ve analiz sonucundan da görüleceği üzere, proje yöneticileri tüm faaliyetleri benzer programlar yardımıyla etkili bir şekilde planlayabilir ve öngörülerde bulanabilir. Problemin çözümünde Matlab programından istifade edilmiştir. Ayrıca sonuçlar; Matlab programına benzer olan parçacık sürü optimizasyonu (PSO), karışık tam sayılı doğrusal programlama (MILP), bulanık programlama (FLP) gibi farklı optimizasyon araçları kullanılarak çözümlenebilir.

\section{Kaynakça}

Arditi, D., Tokdemir, O. B., and Suh, K. (2002) "Challenges in line-of-balance scheduling." J. of Construction Engineering and Management, ASCE, Vol. 128, No.1, pp. 545-556.

Azaron, A., Perkgoz, C., and Sakawa, M., (2005) A genetic algorithm approach for time cost trade off in PERT networks. Applied Mathematics And Computation, 168, 1317-1339

Aziz, R. F. (2013) RPERT: Repetitive-Projects Evaluation and Review Technique. Alexandria Engineering Journal, 53, 81-93. 
Ballesteros-Pérez, P., Larsen, G. and González-Cruz, M. (2018) Do Projects Really End Late? On the Shortcomings of The Classical Scheduling Techniques. Journal of Technology and Science Education, 8, 17-33.

Bettemir, O.H. and Birgonul, T. (2016) "Network analysis algorithm for the solution of discrete time-cost trade-off problem", KSCE J. Civ. Eng., 21(4), 1047-1058. https://doi.org/10.1007/s12205-016-1615-x.

Burgan, H.İ. (2020). Venturimetre Deneyinde Gerçek ve Teorik Debi İlişkisi İçin Debi Düzeltme Katsayısının Belirlenmesi. Avrupa Bilim ve Teknoloji Dergisi, (18), 91-98. DOI: 10.31590/ejosat.669941

Chan, A.P.C., (2001) Time-Cost Relationship of Public Sector Projects In Malaysia, International Journal of Project Management, 19, 223-229.

Creemers, S. (2019) The preemptive stochastic resource-constrained project scheduling problem. European Journal of Operational Research, 277, 238-247.

Elazouni, A.M., and Metwally, F.G., (2007) Expanding finance-based scheduling to derive overall optimized project schedules. Journal of Constitution Engineering and Management, 133(1), 86-90.

Eshtehardian, E., Abbasnia, R. ve Afshar, A., (2008) Optimization of Uncertain Construction Time-Cost Trade Off Problem, Advancing and Integrating Construction Education, Resarch \& Practice, 1, 192-200.

Geem, Z. W. (2010) Multi objective Optimization of Time-Cost Trade-Off Using Harmony Search. Journal of Construction Engineering and Management, 136(6), 711-716.

Gürbüz, F., Dinç, M., \& Erdinç, G. (2020) Case Study for Getting Probability Distributions of Some Basic Construction Activities. Avrupa Bilim ve Teknoloji Dergisi, (Özel Sayı), 137-143.

Haghighi, M. H., Mousavi, S. M., Antuchevičienè, J., \& Mohagheghi, V. (2019) A new analytical methodology to handle time-cost trade-off problem with considering quality loss cost under interval-valued fuzzy uncertainty. Technological and Economic Development of Economy, 25(2), 277-299. https://doi.org/10.3846/tede.2019.8422

Haque, K. M., \& Hasin, M. A., (2012) Genetic Algorithm for Project Time-Cost Optimization in Fuzzy Environment. Journal of Industrial Engineering and Management, 5(2), 364-381.

Hegazy, T., (1999) Optimization of construction time-cost trade-off analysis using genetic algorithms. Canadian Journal of Civil Engineering, 26(6), 685-697.

K. El-Rayes, and A. Kandil, (2005) Time-cost-quality trade-off analysis for highway construction, Journal of Construction Engineering and Management 131 (4), pp.477-486. doi: 10.1061/(ASCE)0733-9364(2005)131:4(477)

Karaman, E. ve Kale, S., (2007) Bulanık Hedef Programlama Yöntemi ile Süre Maliyet-Kalite Eniyilemesi, 4. İnşaat Yönetimi Kongresi, $109-118$

Kelley Jr, J. E. (1961). Critical-path planning and scheduling: Mathematical basis. Operations Research, 9(3), 296-320.

Liu, L., Burns, S. A., \& Feng, C. W. (1995) Construction time-cost trade-off analysis using LP/IP hybrid method. Journal Of Construction Engineering And Management, 121(4), 446-454.

Martin, J., Burrows, T.K. ve Pegg, I. (2006) Predicting Construction Duration of Building Projects, Construction Economics, 28, 1-13.

Parveen, S., \& Saha, S. K., (2012) GA Based Multi-Objective Time-Cost Optimization in a Project with Resources Consideration. International Journal of Modern Engineering Research (IJMER), 2(6), 4352-4359.

PMI., (2008). A Guide to The Project Management Body of Knowledge (4 b., Cilt 5). Pennsylvania: Project Management Institue.

Pour, N. S., Modarres, M., \& Moghadam, R. T. (2012) Time-cost-quality trade-off in Project scheduling with linguistic variables. World Applied Sciences Journal, 18(3), 404-413.

Razek, R.H.A.E., Diab, A.M., Hafez, S.M., and Aziz, R.F., (2010) Time cost quality trade-off software by using simplified GA for typical repetitive construction projects. World Academy of Science, Engineering. \& Technology, 61, 312-320.

Shahsavari-Pour, N., Modarres, M., Tavakoli-Moghadam, R., \& Najafi, E. (2010) Optimizing a multi-objectives time-cost-quality tradeoff problem by a new hybrid genetic algorithm. World Applied Science Journal, 10(3), 355-363.

Sorrentino, M., (2013) Genetic Algorithms for Construction Time-Cost-Quality Trade-Off: ARoad Project Case Study. Construction Management, 2, 163-176.

Suhail, S. A. and Neale, R. H. (1994) "CPM/LOB: New methodology to integrate CPM and line of balance." J. of Construction Engineering and Management, ASCE, Vol. 120, No. 3, pp. 667-684.

Thomas, N., G., Michael, M.Y., Skitmore, M., Lam, K.A.C., Varnam, Mark, (2000) The predictive ability of Bromilow's time - cost model, Construction Management and Economics, 19, 165-173 